\title{
Osteopathic Manipulative Treatment for the Treatment of Hospitalized Premature Infants With Nipple Feeding Dysfunction
}

\author{
Gregg C. Lund, DO, MS; Garrett Edwards, DO; Brenda Medlin, MD; David Keller, DO; Bryan Beck, DO; \\ and Jane E. Carreiro, DO
}

Premature newborns and infants are usually required to successfully transition from gavage to nipple feeding using breast or bottle before discharge from the hospital. This transition is frequently the last discharge skill attained. Delayed acquisition of this skill may substantially prolong hospital length of stay. The authors describe a case of hospitalized premature twins who had considerable delays in attaining nipple-feeding skills. Because of their inability to take all feedings by nipple, preparation for surgical placement of gastrostomy tubes was initiated. Before the surgeries were scheduled, the inpatient osteopathic manipulative medicine service was consulted, and the twins received a series of evaluations and osteopathic manipulative treatment (OMT) sessions. During the OMT course, the twins' nipple feeding skills progressed to full oral feeding, which allowed them to be discharged to home without placement of gastrostomy tubes. The authors also review the literature and discuss the development of nipple feeding in premature newborns and infants and the use of OMT in the management of nipple feeding dysfunction.

J Am Osteopath Assoc. 2011:111(1):44-48

remature birth continues to be a substantial problem in the United States. In spite of numerous advances in obstetric care, the National Center for Health Statistics recently

From the Department of Osteopathic Manipulative Medicine at the Touro University College of Osteopathic Medicine in Vallejo, California (Dr Lund), the Department of Osteopathic Manipulative Medicine at the University of New England College of Osteopathic Medicine in Biddeford, Maine (Drs Edwards and Carreiro), and the Maine Medical Center in Portland (Drs Medlin, Keller, and Beck). Dr Lund holds a master of science degree in health informatics.

The clinical work described in the present report occurred during the osteopathic manipulative medicine residencies of Drs Lund and Edwards, who at the time were employees of the University of New England College of Osteopathic Medicine.

Financial Disclosures: None reported.

Address correspondence to Gregg C. Lund, DO, MS, Department of Osteopathic Manipulative Medicine,Touro University College of Osteopathic Medicine, 1310 Club Drive, Vallejo, CA 94592

E-mail:gregg.lund@tu.edu

Submitted April 16, 2010; revision received August 8, 2010; accepted August $23,2010$. reported that rates for premature and low-birth weight newborns continue to increase. ${ }^{1}$ These newborns often require intensive care and, regardless of the sophisticated technology employed, the requirements for their eventual discharge are usually straight-forward.

The American Academy of Pediatrics' recommendations for discharging sick and premature newborns and infants includes exclusive nipple feeding (breast or bottle) and independence from supplemental oxygen without significant apnea or bradycardia. ${ }^{2}$ The transition from gavage to nipple feeding is frequently the last of the recommended criteria accomplished before discharge, the completion of which has been shown to have a great deal of intra- and interhospital variability of timing.3,4 This variability is not likely because of biologic variability in development but rather the effects of individual patients' morbidities or differences in hospital policy.3,4,20

In response to this problem, clinicians have looked for interventions to manage or-better-to prevent these complications so premature newborns and infants can transition home without the need for home nasogastric feedings or gastrostomy tube placement. One possible intervention is osteopathic manipulative treatment (OMT). While this intervention has not been critically studied, we hope the present case will add to the interest and support for a clinical trial of OMT and its effect on poor nipple feeding in developing premature newborns and infants.

\section{Report of Case}

Twin girls were born at $256 / 7$ weeks gestation to a nulliparous woman. In addition to the twin gestation, this pregnancy was complicated by gestational diabetes managed with diet, incompetent cervix (requiring a cerclage at 19 weeks gestation), and premature labor. The mother was admitted to the hospital in premature labor at $236 / 7$ weeks. Indomethacin, ampicillin, and betamethasone were initiated to postpone delivery and improve fetal lung maturity. She was stable until 2 days prior to delivery when twin A's amniotic sac ruptured. The twins were delivered by cesarean section under spinal anesthesia.

Twin A delivered in the vertex presentation and weighed $660 \mathrm{~g}$ with Apgar scores of 5 at 1 minute and 7 at 5 minutes. Twin B delivered in the breech presentation and weighed $950 \mathrm{~g}$ with Apgar scores of 3 at 1 minute and 6 at 5 minutes. Initial resuscitation for both twins included endotracheal intubation, 
positive pressure ventilation, and surfactant administration. On admission to the neonatal intensive care unit, both newborns were placed on mechanical ventilation via an endotracheal tube. Umbilical arterial and venous catheters were placed, and intravenous fluids and antibiotics were initiated.

During her hospital course, twin A required respiratory support for respiratory distress syndrome that developed into chronic lung disease. Mechanical ventilation via endotracheal intubation was used, followed by nasal continuous positive airway pressure and nasal cannula at both high and low flow. This twin was weaned to room air on day of life (DOL) 76. Caffeine was initiated on DOL 1 to facilitate extubation. Other problems complicating the hospital course included nutrition, anemia requiring red blood cell transfusion, and hyperbilirubinemia requiring phototherapy.

Twin B's early respiratory course was more complex. She received respiratory support for respiratory distress syndrome complicated by pulmonary interstitial emphysema that developed into chronic lung disease. She received 2 additional doses of surfactant, mechanical ventilation via endotracheal tube (including high-frequency oscillatory ventilation), nasal continuous positive airway pressure, and nasal cannula at both high and low flow. She was weaned to room air on DOL 49. Caffeine was initiated on DOL 1 to facilitate extubation and daily diuretics were given from DOL 20 to DOL 58. Like twin A, twin $B$ also had problems with nutrition, anemia requiring red blood cell transfusion, and hyperbilirubinemia requiring phototherapy.

Most aspects of the twins' nutritional courses were similar. Parenteral nutrition was initiated on DOL 1 and continued until DOL 22; enteral nutrition was initiated by means of gavage tubes on DOL 6. Nuzzling at the breast began on DOL 53, followed by attempts to breast feed the next day. In both twins, the transition from gavage to nipple feeding was complicated by gastroesophageal reflux in addition to poor nipple feeding. For twin A, ranitidine hydrochloride was initiated on DOL 72 and metoclopramide hydrochloride was initiated on DOL 104. Twin B received the same medications on DOL 90 and DOL 104, respectively.

On DOL 59, the twins were transferred from the neonatal intensive care unit to the pediatric ward and continued under the care of the neonatology service for convalescence and continued discharge preparation. Various interventions were attempted to improve the twins' poor nipple feeding without success, including changes in formula type, breast feeding, continuous drip gavage feeding, alterations in feeding schedule, and increasing caloric density to minimize necessary volume to deliver adequate calories. When the twins' nipple feeding had not improved at $411 / 7$ weeks gestational age, the surgical placement of gastrostomy tubes was discussed with the parents and preparations for surgery began.
On DOL 102 (41 2/7 weeks gestational age), the neonatology team requested that the inpatient osteopathic manipulative medicine (OMM) service be consulted in an attempt to improve the twins' nipple feeding and to avoid the need for surgical placement of gastrostomy tubes. The twins were evaluated and received osteopathic manipulative treatment (OMT) by OMM-certified attending physicians and OMM residents supervised by the attending physicians.

The specific OMT techniques used were left to the discretion of the treating physician and not based on a predetermined protocol. Techniques included soft tissue, balanced ligamentous tension, myofascial release, inhibition pressure, and osteopathy in the cranial field. Specific application of these techniques included the following: osteopathy in the cranial field for cranial decompression; balanced ligamentous tension for somatic dysfunction of the hyoid bone and it's associated musculature; balanced ligamentous tension for somatic dysfunction of the scapula bone, upper thoracic area, respiratory diaphragm, and ribs; inhibition pressure for somatic dysfunction associated with the celiac and super mesenteric plexus; and osteopathy in cranial field and balanced ligamentous tension for somatic dysfunction of the sacrum.

Changes in the prescribed volume or type of feeding (nipple or gavage) were determined by the neonatology attending physician without the input of the OMM service. In accordance with hospital policy, nursing staff recorded the number of total feedings, the number of nipple feedings (attempted and completed), the volume of fluid taken for each feeding, and feeding type on each infant's chart.

For these twins, nipple feeding performance was calculated as the percent of total feeding volume taken by nipple using the formula [nipple volume/(nipple volume + gavage volume) $] \times 100$. The weekly average of nipple feeding performance was calculated for the week before the initiation of OMT and then weekly until the patients were discharged. The weekly average was calculated by adding the daily nipple performance and dividing this total by 7 . Daily notes from nurses and physicians were reviewed by a member of the study team (G.C.L.) to identify any complications related to the OMT.

\section{Results}

The weekly average for total feeding volume by nipple immediately before initiation of OMT was $16.1 \%$ for twin A and $37 \%$ for twin B. On the day OMT was initiated, twin A took $7.9 \%$ and twin B $38.7 \%$ of total feeding volume by nipple. Prior to OMT, the twins exhibited a lack of progress in nipple feeding performance. However, after they began receiving OMT, the twins' nipple feeding appeared to improve. This progress continued and, after receiving OMT almost daily, both twins were taking all feedings by nipple by DOL 122 (43 


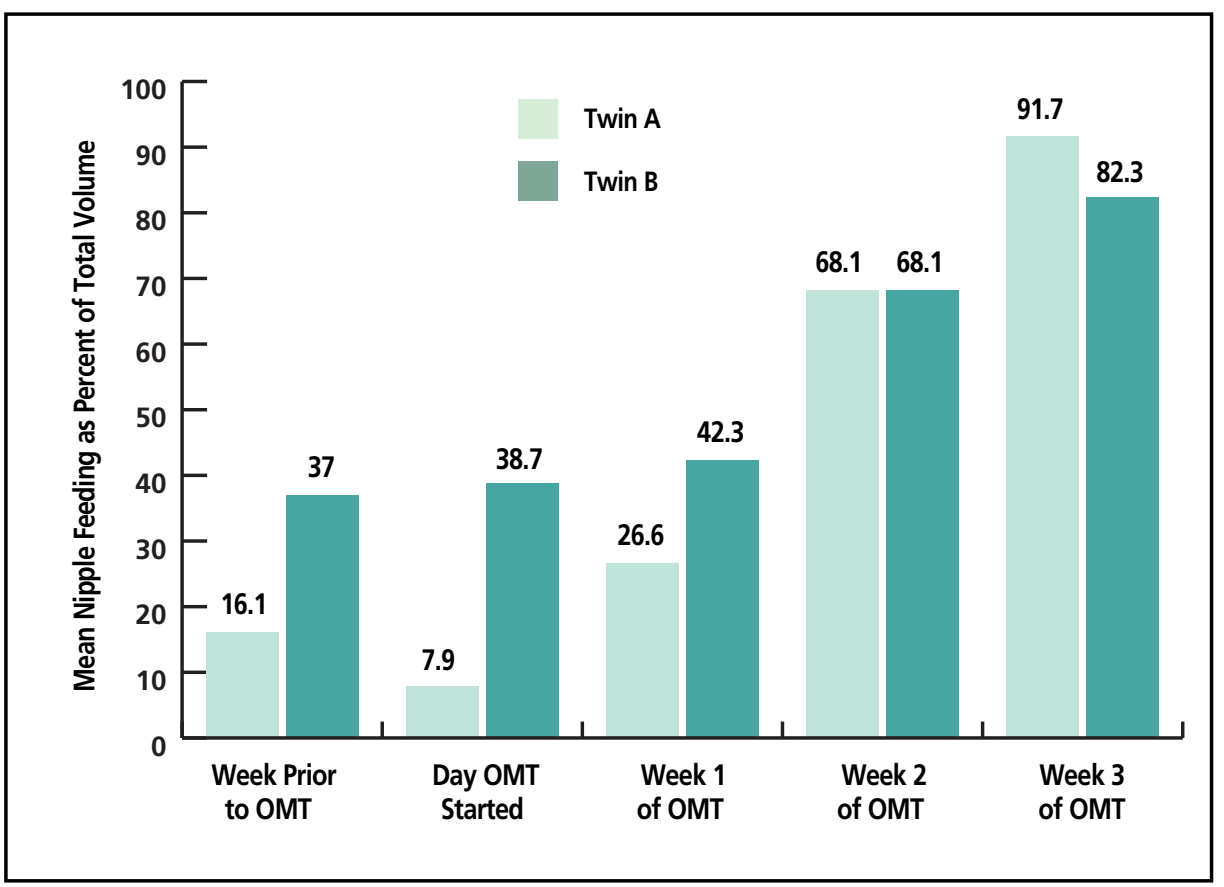

Figure. Feeding performance of premature twin girls before and during osteopathic manipultive treatment (OMT) intervention. All data are the average weekly data, except for "Day OMT started," which is the value for that day.

expression of the milk without generation of substantial negative oral pressure. ${ }^{7}$

In the next phase, pharyngeal swallowing, the milk is delivered from the area between the tongue and hard palate to the esophagus. This process is described in following steps: (1) elevation and retraction of the soft palate with closure of the nasopharynx, (2) upper esophageal sphincter

$1 / 7$ weeks gestation) and discharged to home. Weekly average feeding performance data from the week before OMT initiation to discharge, as well as feeding performance data for the day OMT was initiated, are presented in the Figure.

Review of the medical records, including nurse and physician notes, did not identify any complications related to OMT.

\section{Comment}

Nipple feeding requires a complex set of actions and activities. The process of suck and swallow, whether by breast or bottle, is described in 3 phases: oral, pharyngeal, and esophageal. 5

The oral phase of suck and swallow requires a seal of the mouth on the nipple. Two groups of muscles are related to this function: those which close the jaw (masseter, temporalis, and medial pterygoid) with motor control by cranial nerve $\mathrm{V}$ [trigeminal nerve]) and those that seal the lips (buccinator and orbicularis oris with motor control by cranial nerve VII [facial nerve]). ${ }^{6}$ After the seal is set, the milk is extracted from the nipple and delivered to the oropharynx. Different patterns have been described for this process, depending on whether the milk is delivered by bottle or breast.

With breastfeeding, the anterior portion of the tongue comes in contact with the nipple. However, this action may or may not compress the nipple, and it is not responsible for extraction of milk. $8,9,10$ The nipple is then presented to the hard palate. The middle and posterior tongue move inferiorly with the soft palate and away from the hard palate, generating negative oral pressure. The milk flow from the nipple occurs in response to this negative oral pressure. 8,9 With bottle feeding, newborns and infants can use compression of the nipple against the palate with the tongue and subsequent opening, (3) laryngeal closure at the level of the laryngeal vestibule, (4) tongue loading or ramping, (5) tongue pulsion, and (6) pharyngeal clearance. 11

Effective oral and pharyngeal phases of suck and swallow are dependent upon normal function of the intrinsic muscles of the tongue, as well as the extrinsic stabilizing muscles. The extrinsic muscles stabilize the mandible and hyoid bones, creating a platform upon which the intrinsic movements of the tongue can occur. The stabilizing muscles include the mylohyoid, geniohyoid, digastric, omohyoid, styloglossus, stylohyoid, and hypoglossus. If a stable base is not provided, the intrinsic muscles of the tongue will not be effective, and the coordination of sucking is dysfunctional.

The last phase of suck and swallow is esophageal swallowing. In this phase, contents are delivered from the oropharynx, through the esophagus, and to the stomach by means of peristalsis. 12

Physiologic and structural differences exist between newborns and infants and adults. These differences impact nipple feeding and, in many cases, offer a benefit for newborns and infants. Anatomically, cheek fat pads in newborns and infants narrow the lateral dimension of the oral cavity.12 Newborn and infant tongues, which are larger in scale than adult tongues, further decrease oral cavity size, with the posterior third of the tongue positioned in the oral cavity. In addition, the hyoid bone and the larynx are positioned further forward under the tongue, creating a support during sucking. 8,12

The physiologic development of nipple feeding has been well described. In general, maturation occurs with a faster and more rhythmic sucking rate, greater aggregation of sucks into longer runs, greater aggregation of swallows into runs, and 
greater integration and stability of suck and swallow rhythms.13,14

Adding to a more complete understanding of this development, Lau et al ${ }^{15}$ described a scoring paradigm for the developmental progression of nipple feeding used by premature infants, which includes 5 stages. ${ }^{14}$ Stage 1 consists of arrhythmic expression/compression with little or no suction. Stage 2 involves rhythmic expression/compression (positive pressure produced between the hard palate and tongue) with suction being arrhythmic and of larger amplitude. In Stage 3, the suction becomes increasingly rhythmic, alternating with expression/compression. Stage 4 consists exclusively of rhythmic alternation of suction and expression/compression. Stage 5 consists of increased suction amplitude and increased duration of sucking burst. The inclusion of expression/compression in the system described by Lau et al is unique when compared to other descriptions of development. This difference is likely due to the fact that Lau et al studied bottle feeding instead of breast feeding, in which milk flow is dependent on production of negative oral pressure, not expression/compression. ${ }^{9}$

In addition to developing the actual mechanics of suck and swallow, premature newborns and infants must also develop coordination of suck and swallow with respiration. Swallow can take place at any of the following times during the respiratory cycle: during inspiration or expiration, at the end of inspiration or expiration, or during an apneic event.14,15 For the safest respiration, swallow should not occur during pharyngeal air flow or during an apnea event. Theoretically, the best time for swallow is at the end of inspiration or expiration. As newborns and infants develop, suck and swallow mechanics and breath patterns become more organized and rhythmic. In addition, the swallows occur at times of the respiratory cycle less likely to be associated with aspiration. 14,15

A biologic plausibility exists for OMT as an effective treatment in at least one subgroup of newborns and infants with nipple feeding dysfunction. One such subgroup may be newborns and infants with ineffective coordination of the muscular actions required for suck and swallow because of localized somatic dysfunction. For example, the hyoid bone must be stabilized to create a level platform for the tongue; somatic dysfunction of the stabilizing muscles may shift the hyoid bone laterally or inferiorly. This shift would affect the ability of the intrinsic muscles of the tongue to symmetrically stabilize the nipple against the hard palate and to generate negative oral pressure. The effective application of OMT to these dysfunctions could improve nipple feeding in this subgroup of newborns and infants.

Magoun ${ }^{19}$ described possible support for the use of OMT in premature newborns and infants. He reported that an entrapment neuropathy of the hypoglossal nerve, or cranial nerve XII, as it exits the hypoglossal canal of the cranium, can be associated with abnormal suck and swallow. Osteopathic manipulative treatment of the causative cranial base somatic dysfunction could lead to improved suck and swallow function.

In a small pilot study, Fraval18 investigated the effect of OMT on 6 breast-fed newborns and infants who were younger than 6 months and referred for outpatient evaluation of nipple feeding dysfunction. The data suggested the possibility that OMT may improve nipple feeding. However, the study was limited by the small number of patients, minimal description of the specific feeding dysfunction, and a less traditional outcome, making it difficult to compare to other studies of nipple feeding performance.

In addition to nipple feeding dysfunction, the twins in the present case had other medical problems including chronic lung disease. Though not directly linked with the process of suck and swallow, chronic lung disease in premature newborns and infants has been associated with disordered development of nipple feeding. ${ }^{20}$ The following 2 factors related to this association could have contributed to the nipple feeding dysfunction described in the present case: (1) the associated increased work of breathing and the synchronization of breathing and feeding and (2) the associated somatic dysfunction related to the neck, scapula, and upper chest wall, which could influence the stabilizing muscles used in nipple feeding. The use of OMT for the somatic dysfunction of the chest wall and related structures might positively affect the work of breathing, the synchronization of swallowing, and the functional mechanics of nipple feeding.

While, to our knowledge, no studies have been published on the use of OMT in chronic lung disease related to prematurity, studies have been published on the use of OMT in asthma, which may have a related functional physiology. In a randomized trial of pediatric patients with asthma, OMT was shown to significantly improve pulmonary function as measured by objective pulmonary function testing. ${ }^{21}$

Although OMT has been used in clinical settings to manage nipple feeding dysfunction, to our knowledge, no data are available for the use of OMT to treat hospitalized premature or sick newborns and infants.

\section{Conclusion}

The present report does not prove that OMT is responsible for the improved nipple feeding function in the described premature twins. While the temporal sequence of nipple feeding improvement in both twins following OMT may be coincidental, it does raise the question of association. It is also of interest that no complications related to the OMT were identified. We suggest the use of OMT for the management of nipple feeding dysfunction is a clinical area fertile for future organized investigation.

\section{References}

1. Martin JA, Hamilton BE, Sutton PD, et al. Births: final data for 2006. Natl Vital Stat Rep. 2009;57(7):1-102. 
2. American Academy of Pediatrics Committee on Fetus and Newborn. Hospital discharge of the high-risk neonate. Pediatrics. 2008;122(5):1119-1126.

3. Eichenwald EC, Blackwell M, Lloyd JS, Tran T, Wilker RE, Richardson DK. Interneonatal intensive care unit variation in discharge timing: influence of apnea and feeding management. Pediatrics. 2001;108(4):928-933.

4. Bromiker R, Arad I, Loughran B, Netzer D, Kaplan M, Medoff-Cooper B. Comparison of sucking patterns at introduction of oral feeding and at term in Israeli and American preterm infants. Acta Pædiatr. 2005;94(2):201-204.

5. Miller AJ. Neurophysiological basis of swallowing. Dysphagia. 1986;1(2):91100.

6. Standring S. Gray's Anatomy: The Anatomical Basis of Clinical Practice. 39th ed. New York, NY: Elsevier Churchill Livingstone; 2005.

7. Lau C, Sheena HR, Shulman RJ, Schanler RJ. Oral feeding in low birth weight infants. J Pediatr. 1997;130(4):561-569.

8. Miller JL, Kang SM. Preliminary ultrasound observation of lingual movement patterns during nutritive versus non-nutritive sucking in a premature infant. Dysphagia. 2007;22(2):150-160.

9. Geddes DT, Kent JC, Mitoulas LR, Hartmann PE. Tongue movement and intra-oral vacuum in breastfeeding infants. Early Hum Dev. 2008;84(7):471-477.

10. Eishima K. The analysis of sucking behaviour in newborn infants. Early Hum Dev. 1991;27(3):163-173.

11. Miller AJ. The Neuroscientific Principles of Swallowing and Dysphagia. San Diego, CA: Singular Publication Group; 1999.

12. Delaney AL, Arvedson JC. Development of swallowing and feeding: prenatal through first year of life. Dev Disabil Res Rev. 2008;14(2):105-117.

13. Gewolb IH, Vice FL, Schweitzer-Kenney EL, Taciak VL, Bosma JF. Developmental patterns of rhythmic suckle and swallow in preterm infants. Dev Med Child Neurol. 2001;43(1):22-27.

14. Gewolb IH, Vice FL. Maturational changes in the rhythms, patterning, and coordination of respiration and swallow during feeding in preterm and term infants. Dev Med Child Neurol. 2006;48(7):589-594.
15. Lau C, Smith EO, Schanler RJ. Coordination of suck-swallow and swallow respiration in preterm infants. Acta Paediatr. 2003;92(6):721-727.

16. Lau C, Alagugurusamy R, Schanler RJ, Smith EO, Shulman RJ. Characterization of the developmental stages of sucking in preterm infants during bottle feeding. Acta Paediatr. 2000;89(7):846-852.

17. Sheppard JJ, Fletcher KR. Evidence-based interventions for breast and bottle feeding in the neonatal intensive care unit. Semin Speech Lang. 2007;28(3):204212.

18. Fraval M. A pilot study: osteopathic treatment of infants with a sucking dysfunction. Am Acad Osteopath J. 1998;8(2):25-33.

19. Magoun HI. Entrapment neuropathy of the central nervous system. II. Cranial nerves 1-IV, VI-VIII, XII. J Am Osteopath Assoc. 1968;67(7):779-787.

20. Gewolb IH, Bosma JF, Reynolds EW, Vice FL. Integration of suck and swallow rhythms during feeding in preterm infants with and without bronchopulmonary dysplasia. Dev Med Child Neurol. 2003;45(5):344-348.

21. Guiney PA, Chou R, Vianna A, Lovenheim J. Effects of osteopathic manipulative treatment on pediatric patients with asthma: a randomized controlled trial. J Am Osteopath Assoc. 2005;105(1):7-12.

Editor's Note: In this article, the authors use the term osteopathy in the cranial field to describe the palpatory techniques and osteopathic manipulative treatment used to assess cranial dysfunction and to treat patients for such dysfunction.

American Osteopathic Association policy and the style guidelines of JAOA-The Journal of the American Osteopathic Association prefer the term osteopathic medicine to osteopathy. For this article, the authors requested that the term osteopathy in the cranial field be retained.

\section{JAOA Submissions: Online-Only Content}

JAOA-The Journal of the American Osteopathic Association encourages authors to include additional online-only content (eg, videos, slides) with their manuscript submissions. Contact the JAOA's editorial assistant at jaoa@osteopathic.org for more information. 